\title{
Magnesium bei Hund und Katze - physiologische Aspekte, Messung und Störungen im Magnesiumhaushalt
}

\author{
Nicole Schulz; Arne Güssow; Natali Bauer; Andreas Moritz \\ Klinikum Veterinärmedizin, Institut für Klinische Pathophysiologie und Klinische Laboratoriumsdiagnostik, Justus-Liebig-Universität Gießen
}

\begin{abstract}
Schlüsselwörter
Hypomagnesiämie, Hypermagnesiämie, Magnesiumbedarf, Elektrolytstörungen, Intensivmedizin, ionisiertes Magnesium

\section{Zusammenfassung}

Magnesium ist nach Kalium das intrazelluläre Kation, das in höchster Konzentration im Körper vorkommt. Es spielt eine fundamentale Rolle in nahezu jedem metabolischen Prozess und ist wichtig für die Knochenmineralisierung, die Kontraktion und Relaxation des Muskels sowie die neuronale Erregungsübertragung. Aufgrund seiner Relevanz in der Intensivmedizin kam es in den letzten Jahren zu einem deutlichen Wissenszuwachs hinsichtlich des Verständnisses über die Funktionen von Magnesium im Körper, die Probleme, die zur Störung der Magnesiumhomöostase führen, und labordiagnostische Limitationen. Abweichungen der Serumkonzentration von Magnesium stellen eine der häufigsten Elektrolytstörungen dar und können zu lebensbedrohlichen Zuständen führen. Die meisten Informationen bezüglich der Rolle von Magnesium stammen neben der humanmedizinischen Literatur vor allem aus der Rindermedizin. In den letzten Jahren beschäftigten sich einige wenige Studien auch mit der Bedeutung dieses Elektrolyts bei Hund und Katze.
\end{abstract}

\section{Keywords}

Hypomagnesemia, hypermagnesemia, magnesium requirement, electrolyte disturbances, intensive-care medicine, ionized magnesium

\section{Summary}

Magnesium is the second most abundant intracellular cation after potassium. It plays a vital role in almost every metabolic process in the body and is important for bone mineralization, muscle contraction and relaxation, and neuronal signal transduction. Because of its expanding role in intensive-care medicine, there has been a significant increase in knowledge during recent years regarding the functions of magnesium in the body, problems leading to magnesium disorders, and limitations of laboratory testing. Alterations of serum magnesium constitute one of the most prevalent electrolyte abnormalities in critically ill patients and can lead to life-threatening complications. In addition to human literature, most of the information regarding the role of magnesium is derived from buiatrics. In recent years, a few studies in veterinary medicine have also started to consider the importance of magnesium in dogs and cats.
Korrespondenzadresse

Dr. Nicole Schulz

Klinikum Veterinärmedizin

Institut für Klinische Pathophysiologie

und Klinische Laboratoriumsdiagnostik

der Justus-Liebig-Universität Gießen

Frankfurter Straße 126

35392 Gießen

E-Mail: Nicole.Schulz@vetmed.uni-giessen.de
Magnesium in dogs and cats - physiology, analysis, and magnesium disorders Tierarztl Prax Ausg K Kleintiere Heimtiere 2018; 46: 21-32 http://dx.doi.org/10.15654/TPK-170556 Eingegangen: 19. September 2017 Akzeptiert nach Revision: 19. Dezember 2017

\section{Physiologie}

\section{Funktion und Verteilung von Magnesium im Körper}

Magnesium ist ein essenzielles Mengenelement und ein Kofaktor von mehr als 600 ATP-abhängigen enzymatischen Reaktionen. Es spielt insbesondere im zellulären Energiestoffwechsel eine tragende Rolle und wird beispielsweise bei der oxidativen Phosphorylierung in den Mitochondrien sowie für den anaeroben Glukosemetabolismus benötigt. Magnesium nimmt eine entscheidende Rolle bei der Zellreplikation und der Proteinsynthese ein (23). Es ist bei der Aufrechterhaltung des elektrochemischen Gleichgewichts beteiligt und hilft, eine niedrige intrazelluläre Kalziumkon- zentration aufrechtzuerhalten (17). Magnesium hat einen Einfluss auf die Freisetzung von Neurotransmittern, die Myokardkontraktilität und die Reizübertragung. Darüber hinaus trägt es zur Mineralisation des Knochens bei (27). Ein schwerwiegender Magnesiummangel kann zu gravierenden neuromuskulären Störungen führen $(23,44)$. Aber auch eine subklinische Hypomagnesiämie kann zu einer Verschlechterung bestehender Krankheitszustände beitragen (19). Da Magnesium als Mengenelement im wässrigen Milieu zum Großteil ionisiert vorliegt, also ein positiv geladenes Teilchen darstellt, wird es in der Labordiagnostik als Elektrolyt bezeichnet (109). 
Betrachtet man die Verteilung von Magnesium im Körper, finden sich $60 \%$ im Knochen, 38\% im Weichgewebe und nur 1-2\% im Extrazellulärraum (107). Zu Letztgenanntem zählt auch das Magnesium im Plasma (tMg = Gesamtmagnesium). Dieses lässt sich, vergleichbar dem Kalzium, wiederum in drei Fraktionen aufteilen: das freie ionisierte Magnesium (iMg, 63\%), das an Proteine gebundene Magnesium (31\%) und das mit Anionen (u. a. Zitrat, Phosphat, Bikarbonat und Laktat) Komplexe bildende Magnesium $(6 \%)(96,107)(\triangleright$ Abb. 1). Von den drei Fraktionen hat das iMg die größte biologische Aktivität. Es wird angenommen, dass iMg die Fraktion des Gesamtmagnesiums darstellt, die im Rahmen pathologischer Zustände schnellen Veränderungen unterliegt $(4,95)$.

\section{Regulation des Magnesiumhaushalts}

Die Magnesiumhomöostase im Körper wird durch die Balance zwischen intestinaler Absorption und renaler Exkretion und Reabsorption bestimmt. Obwohl einige Hormone an der Magnesiumregulation beteiligt sind, gibt es keines, das die Magnesiumhomöostase spezifisch reguliert (119). Man nimmt an, dass während der Evolution ein Überschuss an Magnesium vorlag, wodurch der Magnesiumbedarf durch die Absorption aus dem Darm gedeckt und überflüssiges Magnesium über die Nieren ausgeschieden wurde $(65,119)$.

Insgesamt werden 30-40\% des oral aufgenommenen Magnesiums intestinal resorbiert, der Rest wird über die Fäzes ausgeschieden. Bei geringer oraler Magnesiumaufnahme kann die intestinale Resorption bis auf einen Anteil von $80 \%$ ansteigen (77). Bei Hunden (100) und Katzen (129) findet die intestinale Magnesiumresorption primär im Dickdarm statt. Ein Großteil des Magnesiums wird parazellulär entlang der „tight junctions“ der intestinalen Epithelzellen aufgenommen $(27,77)$. Im Kolon erfolgt zu-

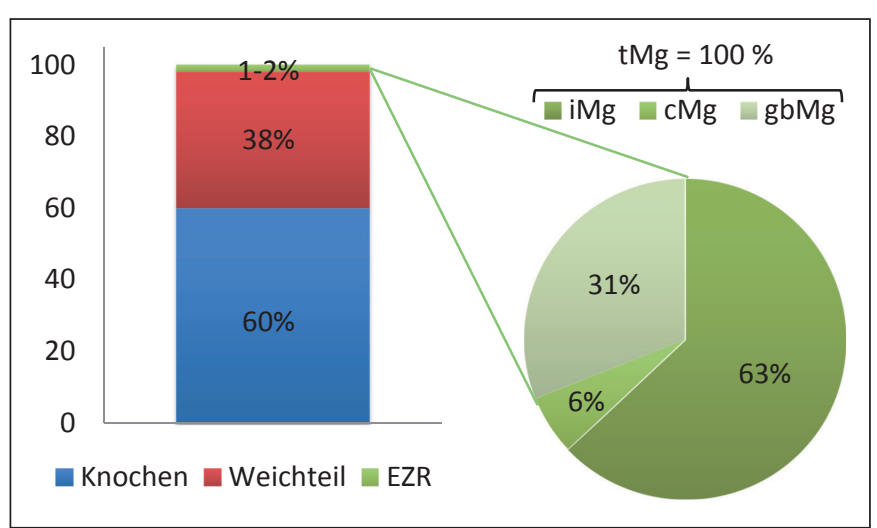

Abb. 1 Verteilung von Magnesium im Körper sowie im Serum/Plasma des Hundes $(96,107) . E Z R=$ Extrazellulärraum, $\mathrm{tMg}=$ Gesamtmagnesium, $\mathrm{iMg}=$ ionisiertes Magnesium, $\mathrm{cMg}=$ mit Anionen Komplexe-bildendes Magnesium, $\mathrm{gbMg}=$ an Protein gebundenes Magnesium

Fig. 1 Distribution of magnesium in the body and serum/plasma of the dog $(96,107) . E Z R=$ extracellular space, $t M g=$ total magnesium, $\mathrm{iMg}=$ ionized magnesium, $\mathrm{cMg}=$ magnesium complexed with anions, $\mathrm{gbMg}=$ proteinbound magnesium. dem eine transzelluläre Magnesiumabsorption mittels spezifischer Transportproteine $(77,118)$. Die intestinale Magnesiumabsorption korreliert zudem mit dem Magnesiumgehalt in der Nahrung (36). Parathormon (PTH) und Vitamin $\mathrm{D}_{3}$ wird ein positiver Effekt auf die Magnesiumresorption im Darm zugesprochen $(27,77)$.

Ein Großteil des im Knochen befindlichen Magnesiums dient als Reservoir, um bei einem Magnesiummangel die physiologische extrazelluläre Magnesiumkonzentration konstant zu halten $(8,88)$. Die Kapazität des Knochens, Schwankungen des extrazellulären Magnesiumspiegels zu puffern, nimmt beim Menschen mit dem Alter ab (119). Bei dauerhaftem Magnesiummangel kann der Knochen bei Mensch und Tier spröder und frakturanfälliger werden $(18,88)$.

Für die Regelung des Magnesiumhaushalts sind jedoch primär die Nieren verantwortlich. So werden 70-80\% des Gesamtmagnesiums im Serum glomerulär filtriert und unter physiologischen Bedingungen zu 95\% tubulär reabsorbiert. Lediglich 3-5\% des glomerulär filtrierten Magnesiums werden mit dem Harn ausgeschieden (23). Im Zustand des Magnesiummangels kann die renale Ausscheidung deutlich reduziert werden, während bei einer Magnesiumaufnahme im Überschuss eine Steigerung der renalen Ausscheidung stattfindet $(7,27)$. Etwa $10-15 \%$ des filtrierten Magnesiums werden im proximalen Tubulus reabsorbiert, $60-70 \%$ anschließend im dicken aufsteigenden Ast der Henle-Schleife (27, 76). Die Pars convoluta des distalen Tubulus bestimmt die endgültige Magnesiumausscheidung über den Harn. Bei einem Magnesiummangel kann die Absorption durch spezifische Transportproteine auf 70-80\% des im Bereich der Henle-Schleife nicht resorbierten Magnesiums gesteigert werden (22). Magnesium wird zudem während der Laktation in die Milch $(1,2)$ und in geringen Mengen in den Schweiß (106) sezerniert.

Vermutlich können PTH, Kalzitonin, Vitamin $\mathrm{D}_{3}$, antidiuretisches Hormon, Aldosteron und Insulin zusätzlich die renale Magnesiumrückresorption steigern $(27,85)$. Eine niedrige Magnesiumkonzentration kann jedoch auch eine verminderte PTH-Synthese und ein reduziertes Ansprechen der Endorgane auf PTH zur Folge haben $(33,55)$. Hierbei erweist sich eine bestehende Hypokalzämie häufig als resistent gegenüber einer Behandlung mit Kalzium, bis die gleichzeitig vorliegende Hypomagnesiämie korrigiert ist (92).

\section{Messung von Magnesium}

Die Messung von tMg im Plasma oder Serum stellt die am häufigsten genutzte Methode zur Bestimmung von Magnesium in der Routinediagnostik dar. Da tMg zu ca. 30\% an Proteine gebunden ist (9), kann eine Hypalbuminämie eine niedrige tMg-Konzentration (Pseudohypomagnesiämie) bedingen und somit $\mathrm{zu}$ einer falschen Interpretation des Magnesiumstatus führen (42, 51, 93, 94, 107). Bestimmte Antikoagulanzien (z. B. EDTA, Zitrat, Oxalat) binden Magnesium, weshalb deren Einsatz vermieden werden sollte. Eine hochgradige Hyperbilirubinämie kann bei Verwen- 
dung der Messmethode mit Methylthymolblau ebenfalls falsch niedrige Magnesiumkonzentrationen zur Folge haben $(137,139)$. Umgekehrt können eine Hämolyse und eine verzögerte Serumseparierung aufgrund des hohen $\mathrm{tMg}$-Gehalts der Erythrozyten (fast dreimal so hoch wie im Plasma) falsch hohe tMg-Messwerte bedingen $(107,109)$.

Nur etwa $1 \%$ des tMg liegt extrazellulär vor und teilweise besteht eine unzureichende Korrelation zwischen Magnesiumkonzentration im Serum und klinischem Bild, weshalb einige Autoren zur Bewertung des Magnesiumstatus die Bestimmung von intrazellulärem Magnesium bevorzugen (27, 30, 42, 51). Trotz gewisser Vorzüge ist die Messung von intrazellulärem Magnesium aufwendig und wenig routinetauglich $(4,11,95)$.

Seit den 1990er Jahren sind ionenselektive Elektroden erhältlich, die die Bestimmung von iMg ermöglichen (95). Seitdem findet die Messung des iMg im Serum vermehrt Interesse (30, 34, $57,104,114,124)$. Da ein enges Gleichgewicht zwischen extra- und intrazellulärem iMg besteht, wird angenommen, dass die im Serum bestimmte iMg-Konzentration die im Körper vorliegende iMg-Konzentration gut widerspiegelt $(27,84)$. Im Gegensatz zu
tMg bleibt beim iMg die Konzentration von einer bei kranken Tieren und Menschen häufig auftretenden Änderung der Serumproteinkonzentration unberührt, ist jedoch in geringem Maße vom $\mathrm{pH}$-Wert abhängig. Eine Azidose führt zu einer erhöhten, eine Alkalose zu einer verminderten iMg-Konzentration (106, 131, 132). Zudem interferiert die Messung von Magnesiumionen mit Kalziumionen, doch erfolgt eine automatische Korrektur durch die Gerätesoftware (95). Es konnte aber beobachtet werden, dass bei sehr hohen Kalziumkonzentrationen auch die gemessene iMg-Konzentration deutlich anstieg (138).

Versuche, anhand des $\mathrm{tMg}$-Gehalts auf die iMg-Konzentration rückzuschließen, erbrachten unbefriedigende Ergebnisse (30, 42, 125). Die schlechte Korrelation von iMg und tMg zeigt sich daran, dass eine erniedrigte $\mathrm{tMg}$-Konzentration bei humanen Patienten auf Intensivstationen in mehr als $80 \%$ der Fälle nicht durch Messung des iMg bestätigt werden konnte (125). Entsprechend der Empfehlung, ionisiertes Kalzium (iCa) zum Nachweis eines Kalziummangels zu bestimmen (97), wird die direkte Messung des iMg als notwendig erachtet, um eine korrekte Aussage über den Magnesiumstatus treffen zu können (30). \ Tab. 1 gibt einen
Tab. 1

Referenzintervalle für Gesamtmagnesium (tMg) und ionisiertes Magnesium (iMg) bei Hunden und Katzen

Table 1

Reference intervals for total magnesium (tMg) and ionized magnesium (iMg) in dogs and cats.

\begin{tabular}{|c|c|c|c|c|}
\hline & Referenzintervall & Tierzahl & Analysegerät & Quelle \\
\hline \multicolumn{5}{|c|}{ Hund } \\
\hline \multirow[t]{3}{*}{$\mathrm{tMg}$} & $\begin{array}{l}1,7-2,5 \mathrm{mg} / \mathrm{dl} \\
(0,70-1,03 \mathrm{mmol} / \mathrm{l})\end{array}$ & 46 & $\begin{array}{l}\text { Synchron Clinical System CX4 und CX3 } \Delta, \\
\text { Beckman }\end{array}$ & 48 \\
\hline & $\begin{array}{l}1,89-2,51 \mathrm{mg} / \mathrm{dl} \\
(0,78-1,03 \mathrm{mmol} / \mathrm{l})\end{array}$ & 93 & $\begin{array}{l}\text { Hitachi } 911 \text { System Analyzer, Boehringer } \\
\text { Mannheim }\end{array}$ & 60 \\
\hline & $\begin{array}{l}1,9-2,5 \mathrm{mg} / \mathrm{dl} \\
(0,78-1,03 \mathrm{mmol} / \mathrm{l})\end{array}$ & 101 (1-8 Jahre) & $\begin{array}{l}\text { Cobas } 6000 \text { C } 501 \text { Chemistry Analyzer, } \\
\text { ROCHE Diagnostics }\end{array}$ & 63 \\
\hline \multirow[t]{6}{*}{ iMg } & $0,42-0,58 \mathrm{mmol} / \mathrm{l}$ & $\begin{array}{l}30 \text { (15 weiblich, } 15 \text { männlich, } \\
17 \text { Rassen, 1-13 Jahre) }\end{array}$ & $\begin{array}{l}\text { NOVA CRT } 8 \text { Electrolyte Analyzer, Nova } \\
\text { Biomedical }\end{array}$ & 114 \\
\hline & $\begin{array}{l}1,03-1,36 \mathrm{mg} / \mathrm{dl} \\
(0,42-0,56 \mathrm{mmol} / \mathrm{l})\end{array}$ & 61 & $\begin{array}{l}\text { NOVA CRT } 8 \text { Electrolyte Analyzer, Nova } \\
\text { Biomedical }\end{array}$ & 57 \\
\hline & $0,25-0,41 \mathrm{mmol} / \mathrm{l}$ & keine Angabe & Stat Profile, Nova Biomedical & 43 \\
\hline & $\begin{array}{l}0,38-0,55 \mathrm{mmol} / \mathrm{l} \\
0,21-0,41 \mathrm{mmol} / \mathrm{l}\end{array}$ & $\begin{array}{l}30 \text { Adulte } \\
44 \text { Welpen (28 Tage) }\end{array}$ & Nova Stat Profile M, Nova Biomedical & 72 \\
\hline & $0,25-0,41 \mathrm{mmol} / \mathrm{l}$ & 22 & Stat Profile, Nova Biomedical & 31 \\
\hline & $0,4-0,52 \mathrm{mmol} / \mathrm{l}$ & 101 (1-8 Jahre) & Nova 8, Nova Biomedical & 63 \\
\hline \multicolumn{5}{|c|}{ Katze } \\
\hline \multirow[t]{2}{*}{$\mathrm{tMg}$} & $\begin{array}{l}1,6-2,4 \mathrm{mEq} / \mathrm{l} \\
(0,8-1,2 \mathrm{mmol} / \mathrm{l})\end{array}$ & 25 & keine Angabe & 111 \\
\hline & $\begin{array}{l}1,3-2,6 \mathrm{mg} / \mathrm{dl} \\
(0,5-1,1 \mathrm{mmol} / \mathrm{l})\end{array}$ & 10 & $\begin{array}{l}\text { Cobas Mira discrete batch chemistry } \\
\text { Analyser, Roche Diagnostic Systems }\end{array}$ & 124 \\
\hline \multirow[t]{4}{*}{ iMg } & $0,47-0,59 \mathrm{mmol} / \mathrm{l}$ & 36 (0,5-14 Jahre) & $\begin{array}{l}\text { NOVA CRT } 8 \text { Electrolyte Analyzer, Nova } \\
\text { Biomedical }\end{array}$ & 115 \\
\hline & $0,43-0,58 \mathrm{mmol} / \mathrm{l}$ & keine Angabe & Stat Profile, Nova Biomedical & 45 \\
\hline & $0,47-0,63 \mathrm{mmol} / \mathrm{l}$ & $\begin{array}{l}40 \text { (20 weiblich, } 20 \text { männlich, } \\
10 \text { Monate-14 Jahre) }\end{array}$ & $\begin{array}{l}\text { NOVA CRT } 8 \text { Electrolyte Analyzer, Nova } \\
\text { Biomedical }\end{array}$ & 34 \\
\hline & $\begin{array}{l}1,09-1,28 \mathrm{mg} / \mathrm{dl} \\
(0,45-0,53 \mathrm{mmol} / \mathrm{l})\end{array}$ & 10 & NOVA SP8 Analyser, Nova Biomedical & 124 \\
\hline
\end{tabular}


Tab. 2 Magnesiumgehalt verschiedener Futtermittel (65).

Table 2 Magnesium content of various feeds (65).

\begin{tabular}{|c|c|}
\hline Futtermittel & $\begin{array}{l}\text { Magnesium (mg pro } \\
100 \mathrm{~g} \text { Futtermittel) }\end{array}$ \\
\hline \multicolumn{2}{|l|}{ Fleisch } \\
\hline - Rind, fettarm & 21 \\
\hline - Schwein, Kotelett & 24 \\
\hline - Pferd, fettarm & 20 \\
\hline - Huhn, Brust & 30 \\
\hline - Pute, Brust & 46 \\
\hline \multicolumn{2}{|l|}{ Andere tierische Bestandteile } \\
\hline - Huhn, Leber & 21 \\
\hline - Schwein, Leber & 21 \\
\hline - Rind, Sehnen & 9 \\
\hline - Rind, Pansen, geputzt & 17 \\
\hline Fleisch-Knochen-Mehl > 30\% Asche & 250 \\
\hline \multicolumn{2}{|l|}{ Fisch } \\
\hline - Hering & 23 \\
\hline - Schellfisch & 15 \\
\hline - Kabeljau & 15 \\
\hline \multicolumn{2}{|l|}{ Tierische Erzeugnisse } \\
\hline - Vollmilch & 10 \\
\hline - Joghurt, 3,5\% Fett & 12 \\
\hline - Eier ohne Schale & 10 \\
\hline \multicolumn{2}{|l|}{ Gemüse und Obst } \\
\hline - Kartoffel, gekocht & 20 \\
\hline - Karotte & 20 \\
\hline - Apfel & 3 \\
\hline \multicolumn{2}{|l|}{ Getreide } \\
\hline - Gerste, zerkleinert, aufgeschlossen & 115 \\
\hline Weizen, zerkleinert, aufgeschlossen & 115 \\
\hline Reis, poliert, roh & 13 \\
\hline - Weizenmehl Typ 405 & 50 \\
\hline - Haferflocken, entspelzt & 170 \\
\hline - Nudeln & 35 \\
\hline
\end{tabular}

Überblick über Referenzbereiche für $\mathrm{tMg}$ und $\mathrm{iMg}$ bei Hund und Katze. Während die Messung von tMg in Deutschland in den meisten kommerziellen veterinärmedizinischen Laboren zu den etablierten Parametern gehört, wird die iMg-Messung nicht routinemäßig angeboten. Bei Laboren, die eine iCa-Messung vornehmen, kann nachgefragt werden, ob auch eine iMg-Messung möglich ist, da hierzu häufig die gleiche ionenselektive Elektrode wie für die iCa-Bestimmung Verwendung findet.

\section{Magnesiumversorgung}

Für den adulten Hund wird eine tägliche Magnesiumzufuhr von 10-12 mg/kg Körpermasse empfohlen, um den Bedarf zu decken. Bei gesunden Hunden reichen 0,05-0,09 g Magnesium pro $100 \mathrm{~g}$ Trockenalleinfutter hierzu aus (65). Eine mangelhafte Magnesiumversorgung kann zahlreiche Gründe haben. Viele Hunde- und teilweise auch Katzenbesitzer bereiten das Futter für ihre Tiere selbst $\mathrm{zu}$ oder stellen auf biologisch artgerechte Rohfütterung (BARF) um $(32,99)$. Bei fehlender Verwendung magnesiumreicher Futtermittel kommt es in seltenen Fällen zu einer suboptimalen Versorgung $(32,65)$. Einen Überblick über den Magnesiumgehalt verschiedener Futterkomponenten gibt $>$ Tab. 2. Faserreiche Diäten oder Diäten mit einem hohen Anteil an freien Fettsäuren, Oxalat, Phosphat und Phytinsäure vermindern die intestinale Magnesiumabsorption $(87,119)$. Während der Trächtigkeit, der Laktation und im Wachstum besteht ein erhöhter Magnesiumbedarf (65, 119). Eine unzureichende wie auch eine übermäßige Magnesiumzufuhr kann sich im Blut durch eine zu niedrige bzw. zu hohe Magnesiumkonzentration manifestieren (65).

\section{Störungen im Magnesiumhaushalt}

\section{Allgemeine klinische Aspekte}

Die klinische und therapeutische Bedeutung von Magnesium hat in den letzten 20 Jahren im Bereich der Intensivmedizin bei Mensch und Tier wachsende Beachtung gefunden $(30,44,74)$. Studien zufolge besteht insbesondere bei kritisch kranken Patienten ein erhöhtes Risiko für die Entwicklung einer Hypomagnesiämie, sodass die Bestimmung von Magnesium mittlerweile nicht nur in der Human- $(30,74)$, sondern auch in der Veterinärmedizin in vielen Intensivstationen zur Routinediagnostik gehört (45, 46, 111). So können insbesondere schwerwiegende Erkrankungen wie beispielsweise eine diabetische Ketoazidose bei der Katze (71), Septikämie und Traumata bei Mensch, Hund und Pferd (60, 104, $106,113)$, aber auch renale und gastrointestinale Störungen bei Mensch und Tier $(44,70,74)$ für eine Hypomagnesiämie prädisponieren. Durch parenterale Infusionstherapie $(19,74)$, Peritoneal- und Hämodialyse $(19,21,44,112)$, Bluttransfusionen (Zitratblut) (44) und Gabe von Diuretika und Protonenpumpeninhibitoren $(13,122)$ kann eine Hypomagnesiämie hervorgerufen oder verschlimmert werden.

Wie in human- und veterinärmedizinischen Studien festgestellt wurde, kann eine Hypomagnesiämie lebensbedrohliche kardiovaskuläre und neuromuskuläre Störungen $(45,68)$ sowie eine refraktäre Hypokaliämie zur Folge haben $(27,41,90)$, die gegebenenfalls den Zustand kritisch kranker Patienten weiter verschlechtert. In der Humanmedizin zählt die Hypomagnesiämie zu den häufigsten Elektrolytstörungen von Patienten auf Intensivstationen (80) und geht oft mit einer ungünstigen Prognose einher. So ergaben sich Mortalitätsraten von $30-70 \%(59,80,127)$. Bei Hunden wurde die Prävalenz einer Hypomagnesiämie (tMg) in Intensivstationen mit 
50-54\% bestimmt, wobei insbesondere Patienten im Schock und mit Traumata betroffen waren $(60,123)$. Im Vergleich dazu betrug die Prävalenz einer Hypomagnesiämie ( $\mathrm{tMg}$ ) bei allgemein stationär behandelten Hunden nur 6\% (48). Toll et al. (111) ermittelten bei $12-28 \%$ der Katzen in Intensivstationen eine Hypomagnesiämie (tMg), wobei es sich vor allem um Tiere mit einer diabetischen Ketoazidose oder inadäquater Nahrungsaufnahme handelte.

Eine Magnesiumsubstitution ist bei solchen Patienten sinnvoll. Darüber hinaus kommt Magnesium zur adjuvanten Therapie bei verschiedenen Krankheitszuständen zum Einsatz $(44,74)$. Ihm wird vor allem in der Behandlung von kardialen Arrhythmien bei Hund und Mensch ein prophylaktischer und zum Teil therapeutischer Effekt zugeschrieben $(10,116)$. Zudem konnte gezeigt werden, dass Magnesium beim Hund den zerebralen Blutfluss nach einer Reanimation aufrechterhält (121) und Vasospasmen vermindert (66). Hunde, die vor einer elektrischen ventrikulären Defibrillation Magnesium erhielten, zeigten schneller wieder eine spontane kardiovaskuläre Zirkulation $(62,121)$. In der Humanmedizin wurde für Magnesium ein neuroprotektiver Effekt bei Hirntraumata und Schlaganfällen nachgewiesen und die Verabreichung von Magnesium senkt bei diesen Patienten signifikant die Mortalität $(26,64,74,103)$.

Bei Menschen mit akutem Asthma bronchiale führt die Gabe von Magnesium durch Blockade von Kalziumkanälen zu einer Relaxation der glatten Muskulatur der Bronchien sowie zu einer verminderten Freisetzung von Histamin und anderen Entzündungsmediatoren und freien Radikalen $(86,102)$. Beim Hund ließ sich ein positiver Effekt von Magnesium auf eine Bronchokonstriktion und pulmonale Hypertension nachweisen $(40,126)$. Magnesiumsulfat stellt aufgrund seiner die Muskelrelaxation unterstützenden Wirkung überdies eine mögliche zusätzliche Therapie bei Hunden und Menschen mit Tetanus dar $(56,101)$.

In der Humanmedizin finden sich Hinweise, dass Magnesium die Insulinsensitivität bei Diabetes mellitus Typ 2 verbessert. Eine Magnesiumsupplementation scheint einen positiven Effekt auf die Regulation des Blutglukosespiegels und die Einhaltung physiologischer Blutzuckerwerte zu haben $(73,83)$. Magnesium wird ferner in der Human- und Tiermedizin ein analgetischer Effekt zugeschrieben. Beim bisher noch eher experimentellen Einsatz von Magnesium zur Analgesie ließ sich der Analgetikabedarf reduzieren $(5,25,91)$. Magnesium soll durch Hemmung der Thrombozytenaggregation und Fibrinogenbindung außerdem eine antikoagulatorische Wirkung haben $(37,89)$. Weiterhin konnte eine antiinflammatorische Wirkung nachgewiesen werden (54).

Wenngleich eine Hypermagnesiämie im Vergleich zur Hypomagnesiämie eher selten auftritt, kann auch sie lebensbedrohlich sein $(30,45,46)$. Bei Hunden in Intensivstationen wurde die Prävalenz einer Hypermagnesiämie (tMg) mit $13 \%$ bestimmt. Die Mortalitätsrate solcher Patienten lag 2,6-fach höher als die von Hunden mit Normomagnesiämie (60). Bei Katzen in Intensivstationen ergab sich die Prävalenz einer Hypermagnesiämie (tMg) mit 14-18\% (111).

\section{Hypomagnesiämie}

\section{Ursachen einer Hypomagnesiämie}

Eine Hypomagnesiämie wird meist durch eine verminderte intestinale Magnesiumaufnahme oder einen erhöhten renalen Verlust verursacht. Eine inadäquate intestinale Aufnahme ist bei unzureichender Nahrungsaufnahme, Diarrhö, Erbrechen oder einer Malabsorption gegeben (44). Auch magnesiumarme Diäten können zu einer Hypomagnesiämie führen $(8,14,15,52,70,117)$. Kimmel et al. (49) veröffentlichten eine Fallserie von fünf Yorkshire Terriern mit einer Proteinverlust-Enteropathie, die eine Hypomagnesiämie mit gleichzeitiger Hypokalzämie aufwiesen. Bei Vorliegen einer akuten Pankreatitis, Parvovirose oder einer Torsio ventriculi konnten dagegen keine signifikanten Veränderungen der $\mathrm{tMg}$ und iMg-Konzentration festgestellt werden $(11,31,57)$.

Bei einem renalen Magnesiumverlust kommen ursächlich eine verminderte tubuläre Rückresorption aufgrund einer polyurischen akuten Nierenerkrankung, eine postobstruktive Diurese sowie ein tubulärer Schaden in Betracht. Diuretika, eine aggressive Infusionstherapie und osmotisch wirksame Substanzen führen ebenfalls zu einer erhöhten Magnesiumdiurese (19, 27, 44). In einer Studie von Schenck (98) zeigten 9\% der Hunde mit chronischer Nierenerkrankung eine Hypomagnesiämie (iMg). Eine andere Studie dokumentierte eine Prävalenz von $94 \%$ für eine Hypomagnesiämie (iMg) bei Katzen in der perioperativen Phase einer Nierentransplantation (124). Da es bei Patienten mit Nierenerkrankungen aufgrund verminderter Albuminkonzentration teilweise zu falsch niedrigen $\mathrm{tMg}$-Messwerten kam (93), bringt die Bestimmung des iMg gewisse Vorteile gegenüber der Messung von $\mathrm{tMg}$ (94).

Auch einige endokrinologische Erkrankungen können zu einer Hypomagnesiämie führen. In einer prospektiven Studie an Katzen wurde bei $62 \%$ der Tiere mit Diabetes mellitus und bei $57 \%$ der Tiere mit diabetischer Ketoazidose eine verminderte iMg-Konzentration im Serum festgestellt. Die iMg-Konzentration fiel dabei früher ab als die tMg-Konzentration (71). Bei diabetischen Hunden ließ sich dagegen keine erniedrigte iMg- und $\mathrm{tMg}$-Konzentration nachweisen (31). Derzeit geht man zudem davon aus, dass bei Katzen mit einer ausgeprägten Hyperthyreose durch gesteigerte renale Magnesiumausscheidung eine Hypomagnesiämie (iMg und $\mathrm{tMg}$ ) hervorgerufen werden kann (35). Auch bei Hunden mit Hypoparathyreoidismus konnte eine erniedrigte iMg-Konzentration dokumentiert werden (98).

Eine Hypomagnesiämie kommt zudem bei schweren Hautverbrennungen, im Wachstum sowie in der Trächtigkeit und der Laktation vor $(1,2,27,72)$. Ähnlich wie bei Rindern kann bei Hunden eine postpartale Hypokalzämie auftreten, doch zeigen Hündinnen eine Tetanie und keine Parese. Als Grund für die unterschiedliche Symptomatik im Vergleich zum Rind wird eine veränderte neuromuskuläre Reizübertragung aufgrund einer Hypomagnesiämie (tMg) angeführt (6).

Schließlich kann eine Hypomagnesiämie durch eine Verschiebung von Magnesium vom extra- in das intrazelluläre Komparti- 
ment bedingt sein. So zeigte beispielsweise eine Studie an Kaninchen, dass die Injektion von Insulin zu einer vermehrten Magnesiumaufnahme in die Zellen führt (87). Eine Redistribution nach Transfusion einer mit Zitrat antikoagulierten Blutkonserve oder aufgrund einer Sepsis kann ebenfalls eine Hypomagnesiämie verursachen $(19,113)$.

Tab. 3 gibt einen Überblick über die Ursachen einer Hypomagnesiämie.

\section{Klinische Symptomatik der Hypomagnesiämie}

Neben vielen unspezifischen Symptomen manifestiert sich eine Hypomagnesiämie bei Hunden und Katzen insbesondere in einer neuromuskulären und kardialen Symptomatik (45). In der $\mathrm{Hu}-$ manmedizin sind ferner Depressionen, Migräne, Epilepsie und
Psychosen beschrieben $(9,38,78)$. Beim Hund ließen sich durch die Gabe von Magnesium (6,5 mg/kg Körpergewicht Magnesiumaspartathydrochlorid) in Kombination mit L-Carnitin stressbedingte Verhaltensauffälligkeiten wie Nervosität, Ängstlichkeit und Geräuschempfindlichkeit günstig beeinflussen (69).

Frühe Studien der 1960er Jahre zeigten bei jungen Hunden mit experimentell induziertem Magnesiummangel in den ersten Lebenswochen vielfältige Symptome wie schlechte Wachstumsrate, zahlreiche dermatologische Probleme (z. B. trockenes Haar, brüchige Krallen), periphere Vasodilatation (Hyperämie der Ohren und Pfoten), Schwellung der Pfoten und plantigrade Fußung durch Erschlaffung des Bandapparats (8, 14, 15, 52, 117, 130). Nach 5-7 Wochen ging der fortschreitende Magnesiummangel mit einer neuromuskulären Übererregbarkeit einher. Es kam zu Tremor, Zuckungen und Tetanien, teilweise mit letalem Ausgang

\begin{tabular}{|c|c|}
\hline Ursachenkomplex & Spezifizierung \\
\hline verminderte Magnesiumaufnahme & $\begin{array}{l}\text { - Anorexie/Inappetenz } \\
\text { - magnesiumarme Futtermittel (v. a. Weidetetanie Rind, Magnesiummangeltetanie } \\
\text { bei Milchkälbern, gezielte Magnesiumreduktion durch Struvit-Stein-Diät bei der } \\
\text { Katze) }\end{array}$ \\
\hline verminderte intestinale Absorption & $\begin{array}{l}\text { Diarrhö/Vomitus, Enteritis, Proteinverlust-Enteropathie } \\
\text { - Darmresektion und -anastomose } \\
\text { - schwerwiegende Lebererkrankung mit Cholestase }\end{array}$ \\
\hline vermehrter renaler Verlust & $\begin{array}{l}\text { - forcierte Infusionstherapie, osmotisch wirksame Substanzen (Mannitol, Hyper- } \\
\text { glykämie) } \\
\text { - polyurische akute Nierenerkrankung, chronische Nierenerkrankung } \\
\text { - tubulärer Schaden (interstitielle Nephritis, renale tubuläre Azidose, akute tubu- } \\
\text { läre Nekrose) } \\
\text { - postobstruktive Diurese } \\
\text { - perioperative Phase nach Nierentransplantation }\end{array}$ \\
\hline endokrinologische Erkrankungen & $\begin{array}{l}\text { - Diabetes mellitus/diabetische Ketoazidose (Katze) } \\
\text { - Hyperparathyreoidismus } \\
\text { - Hyperthyreose (Katze) } \\
\text { - Hyperadrenokortizismus }\end{array}$ \\
\hline $\begin{array}{l}\text { Verschiebung von Magnesium von } \\
\text { extra- nach intrazellulär }\end{array}$ & $\begin{array}{l}\text { - Insulintherapie } \\
\text { - Sepsis/Endotoxämie } \\
\text { - hyperadrenerge Zustände }\end{array}$ \\
\hline Medikamente $(13,75)$ & $\begin{array}{l}\text { - Schleifendiuretika } \\
\text { - ACE-Hemmer, Digoxin } \\
\text { - } \beta \text {-Agonisten } \\
\text { - Protonenpumpeninhibitoren } \\
\text { - Aminoglykoside, Amphotericin B, Polymyxin B, Ticarcillin } \\
\text { - Pentamidin } \\
\text { - Cisplatin, Cyclosporin, Methotrexat } \\
\text { - Pamidronat }\end{array}$ \\
\hline sonstige Ursachen & $\begin{array}{l}\text { - Hautverbrennungen } \\
\text { - Schwitzen } \\
\text { - Wachstum } \\
\text { - Trächtigkeit, postpartale Tetanie (Hund) } \\
\text { - Laktation (v. a. Weidetetanie beim Rind) } \\
\text { - Peritoneal- und Hämodialyse } \\
\text { - Transfusion von Zitratblut } \\
\text { - familiär/genetisch bedingt (Mensch) }\end{array}$ \\
\hline
\end{tabular}

Tab. 3

Ätiologie einer Hypomagnesiämie $(19,27,44,107)$

Table 3

Etiology of hypomagnesemia $(19,27,44,107)$. 
(52, 117). Bei einem Magnesiummangel führt die Verschiebung des intrazellulären Gleichgewichts von Magnesium und Kalzium zu einer vermehrten Freisetzung von Acetylcholin in den neuromuskulären Spalt und somit zu einer gesteigerten Muskelkontraktion $(23,50)$. Zudem werden postsynaptisch gelegene N-Methyl-D-Aspartat(NMDA)-Rezeptoren im zentralen Nervensystem nicht mehr ausreichend von Magnesium blockiert, woraus eine Übererregbarkeit des postsynaptischen Neurons resultiert (61).

Als Beispiel für einen Magnesiummangel mit erhöhter neuromuskulärer Erregbarkeit ist die Weidetetanie des laktierenden Rindes zu nennen, die mit schweren Muskelkrämpfen einhergeht $(107,128)$. Der Magnesiummangel resultiert hierbei aus der Kombination eines erhöhten Kalium- und verminderten Natriumgehalts des jungen Grases, die zu einer reduzierten ruminalen Magnesiumabsorption, einem Magnesiumverlust über die Milch und einer unzureichenden Magnesiummobilisation aus dem Skelett führen (28). Das Auftreten von Krämpfen korreliert hierbei insbesondere mit einer signifikant erniedrigten Magnesiumkonzentration im Liquor der Tiere $(58,128)$. Bei festliegenden Tieren erfolgt die Initialbehandlung durch Infusion magnesiumhaltiger Lösungen. Anschließend ist die orale Gabe von Magnesiumoxid möglich (28).

Störungen der kardialen Reizübertragung stellen ein weiteres häufiges Symptom der Hypomagnesiämie dar. In der Humanmedizin sind vor allem ventrikuläre Tachykardie, Vorhofflimmern und -flattern, supraventrikuläre Tachykardie und Torsade-depointes-Tachykardie (Sonderform der ventrikulären Tachykardien, gekennzeichnet durch ein spindelförmiges Aussehen der Kammerkomplexe im EKG) beschrieben (116). Eine hohe intrazelluläre Magnesiumkonzentration führt während eines Aktionspotenzials am Herzen zu einer Hemmung des Kaliumausstroms aus der Zelle und damit zu einer verzögerten Repolarisation und einer verlängerten Refraktärzeit $(29,116)$. Aufgrund dessen wird Magnesium bei der Behandlung von Arrhythmien ein prophylaktischer und teilweise sogar therapeutischer Effekt zugeschrieben. Insbesondere wenn Arrhythmien nicht auf andere Therapiemaßnahmen ansprechen, sollte eine Magnesiumtherapie in Betracht gezogen werden $(10,116)$. Bei Arrhythmien, die bei Hunden im Rahmen einer Torsio ventriculi auftreten, spielt Magnesium ätiologisch hingegen keine Rolle (11).

Magnesium trägt weiterhin zur Regulation des Gefäßtonus und somit des Blutdrucks bei $(68,133)$. Dabei hat hohe intrazelluläre Magnesiumkonzentration in der glatten Muskulatur der Gefäßwände einen relaxierenden, vasodilatativen Effekt (134). Eine Hypomagnesiämie kann hingegen mit einer systemischen Hypertension und Vasospasmen assoziiert sein $(66,133)$. Ein niedriger intrazellulärer Magnesiumspiegel bedingt zudem eine gestörte renale Kaliumrückresorption am proximalen Tubulus und eine vermehrte Kaliumausscheidung über den Harn $(41,90)$. Ein Magnesiummangel kann so eine Hypokaliämie verschlimmern und sogar unempfänglich für eine Kaliumtherapie machen, bis das Magnesiumdefizit ausgeglichen ist $(27,90)$.
Tab. 4 Klinische Symptome einer Hypomagnesiämie (19, 27, 44, 107)

Table 4 Clinical signs of hypomagnesemia $(19,27,44,107)$.

\begin{tabular}{|c|c|}
\hline Organkomplex & Symptomatik \\
\hline neuromuskulär & $\begin{array}{l}\text { Übererregbarkeit } \\
\text { Tetanien/Muskelkrämpfe, Zuckungen und Tremor } \\
\text { Depressionen, Psychosen, Migräne, Epilepsie } \\
\text { (Mensch) }\end{array}$ \\
\hline kardiovaskulär & $\begin{array}{l}\text { Arrhythmien, Vorhofflimmern/-flattern, (supra-)ventri- } \\
\text { kuläre Tachykardie, Torsade-de-pointes-Tachykardie } \\
\text { (v. a. Mensch) } \\
\text { EKG-Veränderungen: spitze T-Wellen, ST-Strecken- } \\
\text { Senkung, verkürzte PQ- und QRS-Intervalle }(68,135 \text {, } \\
\text { 136) } \\
\text { systemische Hypertension, Vasospasmen }\end{array}$ \\
\hline Skelett & Osteoporose (Mensch) \\
\hline respiratorisch & Bronchokonstriktion \\
\hline
\end{tabular}

Tab. 4 gibt einen Überblick über die Symptome einer Hypomagnesiämie.

\section{Behandlung der Hypomagnesiämie}

Ob eine Hypomagnesiämie bei human- und veterinärmedizinischen Patienten behandlungswürdig ist, hängt von der klinischen Symptomatik und der Schwere der Hypomagnesiämie ab (44). Viele Patienten mit milder Hypomagnesiämie bleiben asyptomatisch und der Blutspiegel normalisiert sich durch die Therapie der zugrundeliegenden Erkrankung. Magnesium hat bei oraler Gabe eine große therapeutische Breite und ist auch in höherer Dosierung von bis zu $2 \mathrm{mEq} / \mathrm{kg} / \mathrm{Tag}$ bei Hunden ohne Nierenerkrankung sicher $(19,27)$. Um bei Hunden signifikante Nebenwirkungen wie Verlust der tiefen Sehnenreflexe, Hypotension und Bradykardie zu induzieren, bedarf es einer drastischen Überdosierung mit Steigerung der Magnesiumkonzentration im Serum auf das Zwei- bis Vierfache des physiologischen Serumspiegels $(45,68)$.

Die für den Hund in der Literatur angegebenen Dosierungen für die orale Magnesium-Substitutionstherapie wurden aus der Humanmedizin abgeleitet. Eine prophylaktische orale Magnesiumsubstitution ist insbesondere bei Patienten mit langfristiger Verabreichung von Schleifendiuretika oder intestinaler Malabsorption anzuraten. Patienten mit ausgeprägten klinischen Symptomen einer Hypomagnesiämie sollten dagegen zunächst eine Infusion von 20\%iger Magnesiumsulfat- oder Magnesiumchloridlösung (Verdünnung mittels 0,9\%iger Kochsalzlösung oder 5\%iger Dextroselösung) erhalten $(27,44)$. In drastischen Fällen kann eine Initialdosis von $0,15-0,3 \mathrm{mEq} / \mathrm{kg}$ über mindestens 5-60 Minuten verabreicht werden (27). Nachfolgend sollte eine kontinuierliche Substitution mittels Dauertropf erfolgen. Eine Überdosierung oder zu schnelle Infusion kann zu Schwäche, Hypotension und Atemlähmung führen. Eine regelmäßige Kontrolle des Blutdrucks und der Elektrolyte ist daher unter Magnesiumtherapie anzuraten (68). 


\begin{tabular}{ll|l|l}
\hline Applikation & Formulierungen & Dosierung & Inkompatibilitäten \\
\hline oral & $\begin{array}{l}\text { Magnesiumglukonat, } \\
\text { Magnesiumoxid, } \\
\text { Magnesiumkarbonat }\end{array}$ & $1-2 \mathrm{mEq} / \mathrm{kg} / \mathrm{d}$ & Magnesiumsulfat hat abführende Wirkung \\
\hline parenteral & $\begin{array}{l}\text { 20\%ige Magnesium- } \\
\text { sulfat- oder Magne- } \\
\text { siumchlorid-Lösung }\end{array}$ & $\begin{array}{l}\text { Notfall-Dosierung: } \\
0,15-0,3 \mathrm{mEq} / \mathrm{kg} \text { über 5-60 min } \\
\mathrm{tMg}<0,1 \mathrm{mmol} / \mathrm{l}:\end{array}$ & $\begin{array}{l}\text { Lipidemulsionen } 10 \% \text {, Dobutaminhydro- } \\
\text { chlorid, bikarbonathaltige Lösung, kal- } \\
\text { ziumhaltige Lösung, laktathaltige Lösung } \\
\text { dann } 0,3-0,5 \mathrm{mEq} / \mathrm{mg} / \mathrm{kg} / \mathrm{d} \text { über 3-5 d }\end{array}$ \\
\hline
\end{tabular}

Tab. 5

Formulierungen und Dosierungen zur Behandlung einer Hypomagnesiämie bei Hund und Katze $(19,27)$

Table 5

Formulations and dosages for the treatment of hypomagnesemia in dogs and cats $(19,27)$.
Eine Übersicht zur Substitution von Magnesium findet sich in Tab. 5.

\section{Hypermagnesiämie}

\section{Ursachen einer Hypermagnesiämie}

Die häufigste Ursache einer Hypermagnesiämie ist Literaturangaben zufolge eine reduzierte glomeruläre Filtrationsrate (GFR) (19). Gründe hierfür sind eine chronische Nierenerkrankung im Endstadium oder akutes Nierenversagen (108). In der Humanmedizin wird bei Patienten mit Hypermagnesiämie ( $\mathrm{tMg}$ ) eine Prävalenz von $43-60 \%$ für eine beeinträchtigte Nierenfunktion angegeben $(20,39)$. Bei chronischen Nierenerkrankungen des Menschen wird in der Regel die Magnesiumkonzentration im Serum bis zu einem Abfall der GFR auf $<30 \mathrm{ml} / \mathrm{min}$ durch eine erhöhte fraktionelle Ausscheidung konstant gehalten (Referenzwert für Erwachsene $\left.100-140 \mathrm{ml} / \mathrm{min} / 1,73 \mathrm{~m}^{2}\right)(21,109)$. Bei fortschreitender Nierenerkrankung kommt es im Folgenden zur Magnesiumretention (112). Bei Hund und Katze wurden vor allem renale und postrenale Azotämien in Zusammenhang mit einer Hypermagnesiämie $(\mathrm{tMg})$ dokumentiert $(46,60,111)$.

In der Humanmedizin finden sich einige Fallberichte zu einer Hypermagnesiämie aufgrund iatrogener parenteraler Überdosierung sowie oraler Gabe von Antazida, magnesiumhaltigen $\mathrm{Ab}$ - führmitteln und Durchführung magnesiumhaltiger Einläufe (16, $47,53)$.

Endokrinologische Störungen können ebenfalls mit einer Hypermagnesiämie assoziiert sein. So wurde eine erhöhte iMg-Konzentration bei Hunden mit Hypoadrenokortizismus (3), diabetischer Ketoazidose $(31,43)$ und sekundärem Hyperparathyreoidismus infolge chronischer Niereninsuffizienz (98) festgestellt. Eine Hypermagnesiämie (tMg und iMg) mit derzeit ungeklärter Ätiologie ist bei Hunden und Katzen mit thorakalen Prozessen wie Neoplasien, Perikard- oder Pleuralergüssen beschrieben $(24,46,111)$.

Für den Menschen, aber auch beim Pferd wird angenommen, dass eine Magnesiumfreisetzung nach Zellschädigung bzw. Zelltod eine Hypermagnesiämie bedingen kann $(30,104,106)$. Als Auslöser gelten Rhabdomyolyse, Tumorlyse-Syndrom, Hämolyse und schwere Septikämien $(106,107)$. Bei Rindern ist eine transiente Hypermagnesiämie (iMg und $\mathrm{tMg}$ ) in Zusammenhang mit der Gebärparese (Milchfieber) beschrieben. Sie kann bei Muttertieren post partum auftreten und wird durch eine Hypokalzämie verursacht. Es wird vermutet, dass es durch eine erhöhte PTH-Konzentration zu einer verstärkten renalen Magnesiumrückresorption sowie zu einer Magnesiumfreisetzung aus dem Knochen kommt $(81,107)$.

Die häufigsten Ursachen einer Hypermagnesiämie sind in Tab. 6 zusammengefasst.

\begin{tabular}{ll|l}
\hline Ursachenkomplex & Spezifizierung \\
\hline $\begin{array}{l}\text { verminderte renale Ausscheidung } \\
\text { postrenale Azotämie }\end{array}$ & Endstadium einer chronischen Nierenerkrankung, akutes Nierenversagen \\
\hline $\begin{array}{l}\text { Dehydratation } \\
\text { verstärkte intestinale Absorption }\end{array}$ & $\begin{array}{l}\text { orale Gabe von magnesiumhaltigen Antazida und Abführmitteln, magnesiumhaltige } \\
\text { Einläufe }\end{array}$ \\
\hline endokrinologische Erkrankungen & $\begin{array}{l}\text { Hypoadrenokortizismus, diabetische Ketoazidose, sekundärer Hyperparathyreoidis- } \\
\text { mus, Hypothyreose }\end{array}$ \\
\hline $\begin{array}{l}\text { Magnesiumfreisetzung nach Zell- } \\
\text { schädigung }\end{array}$ & $\begin{array}{l}\text { Gewebeuntergang (Rhabdomyolyse, Tumorlyse-Syndrom, schwere Septikämie) } \\
\text { (30,104, 106), Hämolyse (107) }\end{array}$ \\
\hline Medikamente (12, 13, 110) & $\begin{array}{l}\text { Infusion magnesiumhaltiger Lösungen } \\
\text { Lithiumintoxikation, Opiatagonisten, ACE-Hemmer, Spironolacton }\end{array}$ \\
\hline weitere Ursachen & $\begin{array}{l}\text { thorakale Prozesse (Neoplasie, Perikard-, Pleuraerguss) } \\
\text { Gebärparese (Milchfieber) beim Rind }\end{array}$ \\
\hline
\end{tabular}

Tab. 6

Ätiologie einer Hypermagnesiämie $(19,27,44,106$, 107)

Table 6

Etiology of hypermagnesemia $(19,27,44,106$, 107). 


\section{Klinische Symptomatik der Hypermagnesiämie}

Das klinische Bild einer Hypermagnesiämie ist insbesondere von kardiovaskulären und neuromuskulären Symptomen geprägt. In der Regel manifestieren sich diese erst bei stark erhöhter Magnesiumkonzentration $(19,108)$. So können beim Hund mit steigendem Magnesiumspiegel ein allmählicher Blutdruckabfall und eine verzögerte Erregungsübertragung am Herzen bis hin zu Kammerflimmern und Asystolie auftreten $(67,68)$. Zudem kann es durch Inhibition der kalziumabhängigen Acetylcholinfreisetzung an der präsynaptischen Membran zu einer Hemmung der neuromuskulären Reizübertragung kommen $(19,108)$. Der Verlust tiefer Sehnenreflexe stellt beim Menschen eines der ersten Symptome einer Hypermagnesiämie dar. Im weiteren Verlauf kann sich eine Muskelschwäche mit schlaffer Paralyse bis hin zur Atemdepression aufgrund der Schwäche der Atemmuskulatur entwickeln $(16,82)$. Beim Menschen ist ferner eine Paralyse der glatten Muskulatur beschrieben, in deren Folge ein Ileus auftreten kann $(79,120)$.

In der humanmedizinischen Literatur wird weiterhin von Schwäche, mentaler Depression sowie Hautrötungen berichtet (19, 27). Zudem kann eine zu hohe orale Magnesiumaufnahme durch Bindung von Wasser an den nicht absorbierten Anteil zu Durchfall führen (119). Bei Katzen und Hunden stellt ein Magnesiumüberschuss in der Nahrung neben alkalischem Harn, proteinreicher und phosphathaltiger Diät sowie familiären Faktoren einen Risikofaktor für die Struviturolithiasis dar (105). Der Markt bietet daher Futtermittel, die durch Ansäuerung des Harns und Vermeidung überschüssiger Protein-, Phosphor- und Magnesiumgehalte der Struvitsteinaufösung und -prophylaxe dienen.

Einen Überblick zur Symptomatik der Hypermagnesiämie gibt Tab. 7.

\section{Behandlung der Hypermagnesiämie}

Ob eine Behandlung der Hypermagnesiämie bei Hund, Katze und Mensch notwendig ist, sollte anhand der klinischen Symptomatik, des Blutdrucks, möglicher EKG-Veränderungen sowie der Höhe der iMg-Konzentration entschieden werden $(27,45)$. Die renale Magnesiumausscheidung lässt sich durch eine gesteigerte Diurese fördern (108). Bei schwerwiegender neuromuskulärer oder kardiovaskulärer Symptomatik ist zudem die Gabe von Kalziumglukonat indiziert. Kalzium antagonisiert Magnesium an der neuromuskulären Endplatte (19). Die gleichzeitige Gabe von Insulin und Glukose kann zusätzlich die Aufnahme von Magnesium in die Zelle fördern (108). In der Regel normalisiert sich der Magnesiumspiegel bei Patienten mit physiologischer Nierenfunktion je nach Ausmaß der Hypermagnesiämie relativ zügig innerhalb von 24 Stunden (45). Bei Patienten mit schwerer renaler Dysfunktion kann jedoch eine Peritoneal- oder Hämodialyse notwendig werden $(21,112)$. Die Therapie ist in $>$ Tab. 8 zusammengefasst.
Tab. 7 Klinische Symptome einer Hypermagnesiämie $(19,67,68)$

Table 7 Clinical signs of hypermagnesemia $(19,67,68)$.

\begin{tabular}{ll}
\hline Organkomplex & Symptomatik \\
\hline neuromuskulär & $\begin{array}{l}\text { Verlust tiefer Sehnenreflexe, Muskelschwäche mit } \\
\text { schlaffer Paralyse, Atemdepression }\end{array}$ \\
\hline kardiovaskulär & $\begin{array}{l}\text { Vasodilatation, systemische Hypotension, Reizüber- } \\
\text { tragungsstörungen im Herzen, Kammerflimmern, } \\
\text { Asystolie }\end{array}$ \\
\hline weitere Symptome & mentale Depression, Hautrötung (Mensch) \\
\hline
\end{tabular}

Tab. 8 Formulierungen und Dosierungen zur Behandlung einer Hypermagnesiämie $(19,27)$

Table 8 Formulations and dosages for the treatment of hypermagnesemia $(19,27)$.

\begin{tabular}{llll}
\hline Mechanismus & Formulierung/Dosierung & Besonderheiten \\
\hline $\begin{array}{l}\text { Steigerung der } \\
\text { Diurese }\end{array}$ & $\begin{array}{l}\text { magnesiumfreie Infusionslö- } \\
\text { sung, osmotisch wirksame Sub- } \\
\text { stanzen (Mannitol), Schleifen- } \\
\text { diuretika }\end{array}$ & $\begin{array}{l}\text { Kontrolle der } \\
\text { Elektrolyt- } \\
\text { konzentrationen }\end{array}$ \\
\hline $\begin{array}{l}\text { Antagonisierung } \\
\text { von Magnesium an } \\
\text { der neuromuskulä- } \\
\text { ren Endplatte }\end{array}$ & $\begin{array}{l}\text { 50\%ige Kalziumglukonat-NaCl- } \\
\text { Lösung: }\end{array}$ & $\begin{array}{l}\text { Eolus: } 50-150 \mathrm{mg} / \mathrm{kg} \text { über } \\
10-20 \mathrm{~min} \text {, dann } \mathrm{kontinuierliche} \\
\text { Infusion von 10-15 } \mathrm{mg} / \mathrm{kg} / \mathrm{h}\end{array}$ & \\
\hline
\end{tabular}

\section{Schlussfolgerung}

Aufgrund der gestiegenen Bedeutung von Magnesium im Bereich der Intensivmedizin bedarf es des Verständnisses der Funktionen und Ursachen für Störungen im Magnesiumhaushalt bei Hunden und Katzen. Abweichungen im Magnesiumhaushalt stellen eine der häufigsten Elektrolytveränderungen bei kritisch kranken Menschen und Tieren dar und können gravierende Auswirkungen auf kardiovaskuläre, neuromuskuläre und metabolische Prozesse im Körper haben.

Trotz der intensiven Forschung und Gewinnung neuer Erkenntnisse im humanmedizinischen Bereich (z. B. Einsatz von Magnesium bei Diabetes mellitus, akutem Asthma bronchiale oder nach einem Schlaganfall $[74,83,103])$, finden sich nur wenige Informationen bezüglich veränderter Magnesiumwerte, deren Ursachen und therapeutischer Relevanz bei hospitalisierten Tieren. Einige Studien in der Veterinärmedizin lassen jedoch vermuten, dass der Bestimmung der Magnesiumkonzentration im Blut auch bei Hunden und Katzen eine entscheidende Rolle beim Management kritisch kranker Patienten zukommt. Insbesondere die iMgKonzentration ist hierbei ins Zentrum des klinischen Interesses gerückt. Umso wichtiger erscheint es, auch in der Veterinärmedizin Ursachen für Veränderungen dieses Parameters bei Hunden 
und Katzen zu erforschen und dessen klinische Relevanz herauszustellen.

\section{Interessenkonflikt}

Die Autoren bestätigen, dass kein Interessenkonflikt besteht.

\section{Literatur}

1. Adkins Y, Zicker SC, Lepine A, Lönnerdal B. Changes in nutrient and protein composition of cat milk during lactation. Am J Vet Res 1997; 58 (4): 370-375.

2. Adkins Y, Lepine AJ, Lönnerdal B. Changes in protein and nutrient composition of milk throughout lactation in dogs. Am J Vet Res 2001; 62 (8): 1266-1272.

3. Adler JA, Drobatz KJ, Hess RS. Abnormalities of serum electrolyte concentrations in dogs with hypoadrenocorticism. J Vet Intern Med 2007; 21 (6): $1168-1173$.

4. Altura BM. Introduction: importance of $\mathrm{Mg}$ in physiology and medicine and the need for ion selective electrodes. Scand J Clin Lab Invest Suppl 1994; 217: 5-9.

5. Anagnostou TL, Savvas I, Kazakos GM, Raptopoulos D, Ververidis H, Roubies $\mathrm{N}$. Thiopental and halothane dose-sparing effects of magnesium sulphate in dogs. Vet Anaesth Analg 2008; 35 (2): 93-99.

6. Aroch I, Srebro H, Shpigel NY. Serum electrolyte concentrations in bitches with eclampsia. Vet Rec 1999; 145 (11): 318-320.

7. Barnes BA, Cope O, Harrison T. Magnesium conservation in the human being on a low magnesium diet. J Clin Invest 1958; 37 (3): 430-440.

8. Barnes BA, Mendelson J. The measurement of exchangeable magnesium in dogs. Metabolism 1963; 12: 184-193.

9. Barragán-Rodríguez L, Rodríguez-Morán M, Guerrero-Romero F. Efficacy and safety of oral magnesium supplementation in the treatment of depression in the elderly with type 2 diabetes: a randomized, equivalent trial. Magnes Res 2008; 21 (4): 218-223.

10. Baty CJ, Sweet DC, Keene BW. Torsades de pointes-like polymorphic ventricular tachycardia in a dog. J Vet Intern Vet 1994; 8 (6): 439-442.

11. Bebchuk TN, Hauptman JG, Braselton WE, Walshaw R. Intracellular magnesium concentrations in dogs with gastric dilatation-volvulus. Am J Vet Res 2000; 61 (11): 1415-1417.

12. Brainard BM, Campbell VL, Drobatz KJ, Perkowski SZ. The effects of surgery and anesthesia on blood magnesium and calcium concentrations in canine and feline patients. Vet Anaesth Analg 2007; 34 (2): 89-98.

13. Buckley MS. Electrolyte disturbances associated with medications in the critically ill. Int J Intensive Care 2012; 83-88.

14. Bunce GE, Jenkins KJ, Phillips PH. The mineral requirements of the dog. III. The magnesium requirement. J Nutr 1962; 76: 17-22.

15. Bunce GE, Chiemchaisri Y, Phillips PH. The mineral requirements of the dog. IV. Effect of certain dietary and physiologic factors upon the magnesium deficiency syndrome. J Nutr 1962; 76: 23-29.

16. Castelbaum A, Donofrio PD, Walker FO, Troost BT. Laxative abuse causing hypermagnesemia, quadriparesis, and neuromuscular junction defect. Neurology 1989; 39 (5): 746-747.

17. Chubanov V, Gudermann T, Schlingmann KP. Essential role for TRPM6 in epithelial magnesium transport and body magnesium homeostasis. Pflugers Arch 2005; 451 (1): 228-234.

18. Cohen L, Kitzes R. Infrared spectroscopy and magnesium content of bone mineral in osteoporotic women. Isr J Med Sci 1981; 17 (12): 1123-1125.

19. Cortés YE, Moses L. Magnesium disturbances in critically ill patients. Compend Contin Educ Vet 2007; 29 (7): 420-427.

20. Crook M. A study of hypermagnesaemia in a hospital population. Clin Chem Lab Med 1999; 37 (4): 449-451.

21. Cunningham J, Rodriguez M, Messa P. Magnesium in chronic kidney disease stages 3 and 4 and in dialysis patients. Clin Kidney J 2012; 5 (Suppl 1): i39-i51.
22. Dai LJ, Ritchie G, Kerstan D, Kang HS, Cole DE, Quamme GA. Magnesium transport in the renal distal convoluted tubule. Physiol Rev 2001; 81 (1): 51-84.

23. de Baaij JH, Hoenderop JG, Bindels RJ. Magnesium in man: implications for health and disease. Physiol Rev 2015; 95 (1): 1-46.

24. de Laforcade, Armelle M, Freeman LM, Rozanski EA, Rush JE. Biochemical analysis of pericardial fluid and whole blood in dogs with pericardial effusion. J Vet Intern Med 2005; 19 (6): 833-836.

25. DeRossi R, Pompermeyer CTD,, Silva-Neto AB, de Barros ALC, Jardim $\mathrm{PH}$, Frazílio FO. Lumbosacral epidural magnesium prolongs ketamine analgesia in conscious sheep. Acta Cir Bras 2012; 27 (2): 137-143.

26. Dhandapani SS, Gupta A, Vivekanandhan S, Sharma BS, Mahapatra AK. Randomized controlled trial of magnesium sulphate in severe closed traumatic brain injury. The Indian Journal of Neurotrauma 2008; 5 (1): 27-33.

27. DiBartola SP, ed. Fluid, Electrolyte, and Acid-Base Disorders in Small Animal Practice, 4th edn. St. Louis, Mo.: Saunders/Elsevier 2012.

28. Dirksen G, Baumgartner W. Innere Medizin und Chirurgie des Rindes, 5. Aufl. Stuttgart: Parey 2006.

29. Duchatelle-Gourdon I, Hartzell HC, Lagrutta AA. Modulation of the delayed rectifier potassium current in frog cardiomyocytes by beta-adrenergic agonists and magnesium. J Physiol 1989; 415: 251-274.

30. Escuela MP, Guerra M, Añón JM, Martínez-Vizcaíno V, Zapatero MD, García-Jalón A et al. Total and ionized serum magnesium in critically ill patients. Intensive Care Med 2005; 31 (1): 151-156.

31. Fincham SC, Drobatz KJ, Gillespie TN, Hess RS. Evaluation of plasmaionized magnesium concentration in 122 dogs with diabetes mellitus: a retrospective study. J Vet Intern Vet 2004; 18 (5): 612-617.

32. Freeman LM, Michel KE. Evaluation of raw food diets for dogs. J Am Vet Med Assoc 2001; 218 (5): 705-709.

33. Freitag JJ, Martin KJ, Conrades MB, Bellorin-Font E, Teitelbaum S, Klahr S et al. Evidence for skeletal resistance to parathyroid hormone in magnesium deficiency. Studies in isolated perfused bone. J Clin Invest 1979; 64 (5): 1238-1244.

34. Gilroy CV, Burton SA, Horney BS, Mackenzie AL. Validation of the Nova CRT8 for the measurement of ionized magnesium in feline serum. Vet Clin Pathol 2005; 34 (2): 124-131.

35. Gilroy CV, Horney BS, Burton SA, Mackenzie AL. Evaluation of ionized and total serum magnesium concentrations in hyperthyroid cats. Can J Vet Res 2006; 70 (2): 137-142.

36. Graham LA, Caeser JJ, Burgen ASV. Gastrointestinal absorption and excretion of Mg 28 in man. Metabolism 1960; 9 (7): 646-659.

37. Gries A, Bode C, Gross S, Peter K, Böhrer H, Martin E. The effect of intravenously administered magnesium on platelet function in patients after cardiac surgery. Anesth Analg 1999; 88 (6): 1213-1219.

38. Gupta SK, Manhas AS, Gupta VK, Bhatt R. Serum magnesium levels in idiopathic epilepsy. J Assoc Physicians India 1994; 42 (6): 456-457.

39. Hashizume N, Mori M. An analysis of hypermagnesemia and hypomagnesemia. Jpn J Med 1990; 29 (4): 368-372.

40. Hirota K, Sato T, Hashimoto Y, Yoshioka H, Ohtomo N, Ishihara H et al. Relaxant effect of magnesium and zinc on histamine-induced bronchoconstriction in dogs. Crit Care Med 1999; 27 (6): 1159-1163.

41. Huang C-L, Kuo E. Mechanism of hypokalemia in magnesium deficiency. J Am Soc Nephrol 2007; 18 (10): 2649-2652.

42. Huijgen HJ, Soesan M, Sanders R, Mairuhu WM, Kesecioglu J, Sanders GT. Magnesium levels in critically ill patients. What should we measure? Am J Clin Pathol 2000; 114 (5): 688-695.

43. Hume DZ, Drobatz KJ, Hess RS. Outcome of dogs with diabetic ketoacidosis: 127 dogs (1993-2003). J Vet Intern Med 2006; 20 (3): 547-555.

44. Humphrey S, Kirby R, Rudloff E. Magnesium physiology and clinical therapy in veterinary critical care. J Vet Emerg Crit Care (San Antonio) 2015; 25 (2): $210-225$.

45. Jackson CB, Drobatz KJ. Iatrogenic magnesium overdose: 2 case reports. J Vet Emer Crit 2004; 14 (2): 115-123.

46. Jeffery U. Hypermagnesemia is associated with increased mortality in canine intensive care unit patients [Poster-Abstract]: ASVCP Meeting 2012. 
47. Khairi T, Amer S, Spitalewitz S, Alasadi L. Severe symptomatic hypermagnesemia associated with over-the-counter laxatives in a patient with renal failure and sigmoid volvulus. Case Rep Nephrol 2014; 2014: 560746.

48. Khanna C, Lund EM, Raffe M, Armstrong PJ. Hypomagnesemia in 188 dogs: a hospital population-based prevalence study. J Vet Intern Med 1998; 12 (4): 304-309.

49. Kimmel SE, Waddell LS, Michel KE. Hypomagnesemia and hypocalcemia associated with protein-losing enteropathy in Yorkshire Terriers: five cases (1992-1998). J Am Vet Med Assoc 2000; 217 (5): 703-706.

50. Konishi M. Cytoplasmic free concentrations of $\mathrm{Ca} 2+$ and $\mathrm{Mg} 2+$ in skeletal muscle fibers at rest and during contraction. Jpn J Physiol 1998; 48 (6): 421-438.

51. Kroll MH, Elin RJ. Relationships between magnesium and protein concentrations in serum. Clin Chem Lab Med 1985; 31 (2): 244-246.

52. Kruse HD, Orent ER, McCollum EV. Studies on magnesium deficiency in animals. Nutrition Reviews 1979; 37 (5): 145-148.

53. Lameris AL, Monnens LA, Bindels RJ, Hoenderop JGJ. Drug-induced alterations in Mg 2+ homoeostasis. Clin Sci 2012; 123 (1): 1-14.

54. Lee C-Y, Jan W-C, Tsai P-S, Huang C-J. Magnesium sulfate mitigates acute lung injury in endotoxemia rats. J Trauma 2011; 70 (5): 1177-1785.

55. Levi J, Massry SG, Coburn JW, Llach F, Kleeman CR. Hypocalcemia in magnesium-depleted dogs: Evidence for reduced responsiveness to parathyroid hormone and relative failure of parathyroid gland function. Metabolism 1974; 23 (4): 323-335.

56. Lipman J, James MF, Erskine J, Plit ML, Eidelman J, Esser JD. Autonomic dysfunction in severe tetanus: magnesium sulfate as an adjunct to deep sedation. Crit Care Med. 1987; 15 (10): 987-988.

57. Mann FA, Boon GD, Wagner-Mann CC, Ruben DS, Harrington DP. Ionized and total magnesium concentrations in blood from dogs with naturally acquired parvoviral enteritis. J Am Vet Med Assoc 1998; 212 (9): 1398-1401.

58. Martens H, Schweigel M. Pathophysiology of grass tetany and other hypomagnesemias. Implications for clinical management. Vet Clin North Am Food Anim Pract 2000; 16 (2): 339-368

59. Martin BJ, Black J, McLelland AS. Hypomagnesaemia in elderly hospital admissions: a study of clinical significance. Q J Med 1991; 78 (286): 177-184.

60. Martin LG, Matteson VL, Wingfield WE, Pelt DR, Hackett TB. Abnormalities of serum magnesium in critically iII dogs: incidence and implications. J Veter Emer Crit 1994; 4 (1): 15-20.

61. Mayer ML, Westbrook GL, Guthrie PB. Voltage-dependent block by Mg2+ of NMDA responses in spinal cord neurones. Nature 1984; 309 (5965): 261-263.

62. McDaniel WC, Curtis JJ, Walls JT, Madsen RW. Effects of magnesium sulfate on electrical ventricular defibrillation of dogs. J Electrocardiol 1998; 31 (2): 137-143

63. Mellema MS, Hoareau GL. Hypomagnesemia in brachycephalic dogs. J Vet Intern Med 2014; 28 (5): 1418-1423.

64. Meloni BP, Campbell K, Zhu H, Knuckey NW. In search of clinical neuroprotection after brain ischemia: the case for mild hypothermia (35 degrees C) and magnesium. Stroke 2009; 40 (6): 2236-2240.

65. Meyer H, Zentek J. Ernährung des Hundes: Grundlagen - Fütterung Diätetik, 8. Aufl. Stuttgart: Enke 2016.

66. Murakawa T, Altura BT, Carella A, Altura BM. Importance of magnesium and potassium concentration on basal tone and 5-HT-induced contractions in canine isolated coronary artery. Br J Pharmacol 1988; 94 (2): 325-334.

67. Nakaigawa $Y$, Akazawa S, Shimizu R, Ishii R, Ikeno S, Inoue $S$ et al. Effects of magnesium sulphate on the cardiovascular system, coronary circulation and myocardial metabolism in anaesthetized dogs. British Journal of Anaesthesia 1997; 79 (3): 363-368.

68. Nakayama T, Nakayama H, Miyamoto M, Hamlin RL. Hemodynamic and electrocardiographic effects of magnesium sulfate in healthy dogs. J Vet Intern Vet 1999; 13 (5): 485-490.

69. Neff U, Wadepuhl M, Kraus A. Magnesiumaspartat-hydrochlorid + L-Carnitin verbessert die körperliche und psychische Leistungsfähigkeit bei Hunden. kleintier konkret 2011; 14 (06): 3-6.
70. Norris CR, Christopher MM, Howard KA, Nelson RW. Effect of magnesium-deficient diet on serum and urine magnesium concentrations in healthy cats. Am J Vet Res 1999; 60 (9): 1159-1163.

71. Norris CR, Nelson RW, Christopher MM. Serum total and ionized magnesium concentrations and urinary fractional excretion of magnesium in cats with diabetes mellitus and diabetic ketoacidosis. J Am Vet Med Assoc 1999; 215 (10): 1455-1459.

72. O'Brien MA, McMichael MA, Le Boedec K, Lees G. Reference intervals and age-related changes for venous biochemical, hematological, electrolytic, and blood gas variables using a point of care analyzer in 68 puppies. J Vet Emerg Crit Care (San Antonio) 2014; 24 (3): 291-301.

73. Orchard TJ. Magnesium and type 2 diabetes mellitus. Arch Intern Med 1999; 159 (18): 2119-2120.

74. Panahi Y, Mojtahedzadeh M, Najafi A, Ghaini MR, Abdollahi M, Sharifzadeh $\mathrm{M}$ et al. The role of magnesium sulfate in the intensive care unit. EXCLI J 2017; 16: 464-482.

75. Perazella MA. Proton pump inhibitors and hypomagnesemia: a rare but serious complication. Kidney Int 2013; 83 (4): 553-556.

76. Quamme GA, Rouffignac C de. Epithelial magnesium transport and regulation by the kidney. Front Biosci 2000; 5: D694-711.

77. Quamme GA. Recent developments in intestinal magnesium absorption. Curr Opin Gastroenterol 2008; 24 (2): 230-235.

78. Ramadan NM, Halvorson H, Vande-Linde A, Levine SR, Helpern JA, Welch K. Low brain magnesium in migraine. Headache 1989; 29 (9): 590-593.

79. Razavi B, Somers D. Hypermagnesemia-induced multiorgan failure. Am J Med 2000; 108 (8): 686-687.

80. Reinhart RA, Desbiens NA. Hypomagnesemia in patients entering the ICU. Crit Care Med 1985; 13 (6): 506-507.

81. Riond JL, Kocabagli N, Spichiger UE, Wanner M. The concentration of ionized magnesium in serum during the periparturient period of non-paretic dairy cows. Vet Res Commun 1995; 19 (3): 195-203.

82. Rizzo MA, Fisher M, Lock P. Hypermagnesemic pseudocoma. Arch Intern Med 1993; 153 (9): 1130-1132.

83. Rodríguez-Morán M, Guerrero-Romero F. Insulin secretion is decreased in non-diabetic individuals with hypomagnesaemia. Diabetes Metab Res Rev 2011; 27 (6): 590-596.

84. Romani AM. Cellular magnesium homeostasis. Arch Biochem Biophys 2011; 512 (1): 1-23.

85. Rouffignac C de, Quamme G. Renal magnesium handling and its hormonal control. Physiol Rev 1994; 74 (2): 305-322.

86. Rowe BH, Camargo CA. The role of magnesium sulfate in the acute and chronic management of asthma. Curr Opin Pulm Med 2008; 14 (1): 70-76.

87. Rude RK. Magnesium metabolism and deficiency. Endocrinol Metab Clin North Am 1993; 22 (2): 377-395.

88. Rude RK, Gruber HE, Wei LY, Frausto A, Mills BG. Magnesium deficiency: effect on bone and mineral metabolism in the mouse. Calcif Tissue Int 2003; 72 (1): 32-41.

89. Ruttmann TG, Montoya-Pelaez LF, James, Michael F M. The coagulation changes induced by rapid in vivo crystalloid infusion are attenuated when magnesium is kept at the upper limit of normal. Anesth Analg 2007; 104 (6): 1475-1480.

90. Ryan MP. Interrelationships of magnesium and potassium homeostasis. Miner Electrolyte Metab 1993; 19 (4-5): 290-295.

91. Ryu J-H, Kang M-H, Park K-S, Do S-H. Effects of magnesium sulphate on intraoperative anaesthetic requirements and postoperative analgesia in gynaecology patients receiving total intravenous anaesthesia. $\mathrm{Br} J$ Anaesth 2008; 100 (3): 397-403.

92. Ryzen E, Wagers PW, Singer FR, Rude RK. Magnesium deficiency in a medical ICU population. Crit Care Med 1985; 13 (1): 19-21.

93. Saha H, Harmoinen A, Nisula M, Pasternack A. Serum ionized versus total magnesium in patients with chronic renal disease. Nephron 1998; 80 (2): $149-152$.

94. Sanders GT, Huijgen HJ, Sanders R. Magnesium in disease: a review with special emphasis on the serum ionized magnesium. Clin Chem Lab Med 1999; 37 (11-12): 1011-1033. 
95. Saris NE, Mervaala E, Karppanen H, Khawaja JA, Lewenstam A. Magnesium. An update on physiological, clinical and analytical aspects. Clin Chim Acta 2000; 294 (1-2): 1-26.

96. Schenck PA. Fractionation of canine serum magnesium. Vet Clin Pathol 2005; 34 (2): 137-139.

97. Schenck PA, Chew DJ. Prediction of serum ionized calcium concentration by use of serum total calcium concentration in dogs. Am J Vet Res 2005; 66 (8): 1330-1336.

98. Schenck PA. Serum magnesium concentrations in association with canine calcium metabolic disorders. J Vet Intern Vet 2008; 22 (3): 796-797.

99. Schlesinger DP, Joffe DJ. Raw food diets in companion animals: a critical review. Can Vet J 2011; 52 (1): 50-54.

100. Schünemann C, Lass N, Meyer H. Intestinaler Stoffwechsel von Calcium, Magnesium und Phosphor beim Hund. J Anim Physiol Anim Nutr (Berl) 1989; 61 (1-5): 193-205.

101. Simmonds EE, Alwood AJ, Costello MF. Magnesium sulfate as an adjunct therapy in the management of severe generalized tetanus in a dog. J Vet Emerg Crit Care (San Antonio) 2011; 21 (5): 542-546.

102. Singh AK, Gaur S, Kumar R. A randomized controlled trial of intravenous magnesium sulphate as an adjunct to standard therapy in acute severe asthma. Iran J Allergy Asthma Immunol 2008; 7 (4): 221-229.

103. Singh H, Jalodia S, Gupta MS, Talapatra P, Gupta V, Singh I. Role of magnesium sulfate in neuroprotection in acute ischemic stroke. Ann Indian Acad Neurol 2012; 15 (3): 177-180.

104. Soliman HM, Mercan D, Lobo, Suzana S M, Mélot C, Vincent J-L. Development of ionized hypomagnesemia is associated with higher mortality rates. Crit Care Med 2003; 31 (4): 1082-1087.

105. Steinbach S. Harnsteine bei Katzen - Ein Update. veterinär spiegel 2015; 25 (03): $107-112$

106. Stewart AJ. Magnesium disorders in horses. Vet Clin North Am Equine Pract 2011; 27 (1): 149-163.

107. Stockham SL, Scott MA. Fundamentals of Veterinary Clinical Pathology, 2nd edn. Ames, Iowa: Blackwell 2008.

108. Swaminathan R. Magnesium metabolism and its disorders. Clin Biochem Rev 2003; 24: 47-66.

109. Thomas L. Labor und Diagnose: Indikation und Bewertung von Laborbefunden für die medizinische Diagnostik, 8. Aufl. Frankfurt am Main: THBooks 2012.

110. Thomason JD, Rockwell JE, Fallaw TK, Calvert CA. Influence of combined angiotensin-converting enzyme inhibitors and spironolactone on serum $\mathrm{K+}, \mathrm{Mg} 2+$, and $\mathrm{Na}+$ concentrations in small dogs with degenerative mitral valve disease. J Vet Cardiol 2007; 9 (2): 103-108.

111. Toll J, Erb H, Bimbaum N, Schermerhorn T. Prevalence and incidence of serum magnesium abnormalities in hospitalized cats. J Vet Intern Med 2002; 16 (3): 217-221.

112. Topf JM, Murray PT. Hypomagnesemia and hypermagnesemia. Rev Endocr Metab Disord 2003; 4 (2): 195-206.

113. Toribio RE, Kohn CW, Hardy J, Rosol TJ. Alterations in serum parathyroid hormone and electrolyte concentrations and urinary excretion of electrolytes in horses with induced endotoxemia. J Vet Intern Med 2005; 19 (2): 223-231.

114. Unterer S, Lutz H, Gerber B, Glaus TM, Hassig M, Reusch CE. Evaluation of an electrolyte analyzer for measurement of ionized calcium and magnesium concentrations in blood, plasma, and serum of dogs. Am J Vet Res 2004; 65 (2): 183-187.

115. Unterer S, Gerber B, Glaus TM, Hässig M, Reusch CE. Evaluation of an electrolyte analyser for measurement of concentrations of ionized calcium and magnesium in cats. Vet Res Commun 2005; 29 (8): 647-659.

116. Vierling W, Liebscher D-H, Micke O, Ehrlich B von, Kisters K. Magnesiummangel und Magnesiumtherapie bei Herzrhythmusstörungen Empfehlungen der Gesellschaft für Magnesium-Forschung e.V. Dtsch Med Wochenschr 2013; 138 (22): 1165-1171.

117. Vitale JJ, Hellerstein EE, Nakamura M, Lown B. Effects of magnesiumdeficient diet upon puppies. Circ Res 1961; 9 (2): 387-394.
118. Voets T, Nilius B, Hoefs S, van der Kemp AW, Droogmans G, Bindels RJ et al. TRPM6 forms the Mg2+ influx channel involved in intestinal and renal Mg2+ absorption. J Biol Chem 2004; 279 (1): 19-25.

119. Vormann J. Magnesium: nutrition and metabolism. Mol Aspects Med 2003; 24 (1-3): 27-37.

120. Weber CA. Hypermagnesemia. A potential complication during treatment of theophylline intoxication with oral activated charcoal and magnesium-containing cathartics. Chest 1989; 95 (1): 56.

121. White BC, Winegar CD, Wilson RF, Krause GS. Calcium blockers in cerebral resuscitation. J Trauma 1983; 23 (9): 788-794.

122. William JH, Nelson R, Hayman N, Mukamal KJ, Danziger J. Proton-pump inhibitor use is associated with lower urinary magnesium excretion. Nephrology (Carlton) 2014; 19 (12): 798-801.

123. Wingfield WE, Matteson VL. Ionized and serum magnesium in normal and critically ill dogs (Abstract). Fifth Internation Veterinary Emergency Critical Care Symposium, San Antonio, Texas 1996; 880.

124. Wooldridge JD, Gregory CR. Ionized and total serum magnesium concentrations in feline renal transplant recipients. Vet Surg 1999; 28 (1):31-37.

125. Yeh DD, Chokengarmwong N, Chang Y, Yu L, Arsenault C, Rudolf J et al. Total and ionized magnesium testing in the surgical intensive care unit Opportunities for improved laboratory and pharmacy utilization. J Crit Care 2017; 42: 147-51.

126. Yoshioka H, Hirota K, Sato T, Hashimoto Y, Ishihara H, Matsuki A. Spasmolytic effect of magnesium sulfate on serotonin-induced pulmonary hypertension and bronchoconstriction in dogs. Acta Anaesthesiol Scand 2001; 45 (4): 435-440.

127. Zafar, Mir Sadaqat Hassan, Wani JI, Karim R, Mir MM, Koul PA. Significance of serum magnesium levels in critically ill-patients. Int J Appl Basic Med Res 2014; 4 (1): 34-37.

128. Zelal A. Hypomagnesemia tetany in cattle. J Adv Dairy Res 2017; 05 (02).

129. Zentek J. Untersuchungen zum Mineralstoffhaushalt der Katze unter besonderer Berücksichtigung des Magnesiums. Dissertation, Tierärztliche Hochschule Hannover 1987.

130. Orent ER, Kruse HD, McCollum EV. Studies on magnesium deficiency in animals II. Species variation in symptomology of magnesium deprivation. Am J Physiol 1932; 101: 454

131. Ben Rayana, Mohammed C, Burnett RW, Covington AK, D‘Orazio P, Fogh-Andersen N, Jacobs E et al. Guidelines for sampling, measuring and reporting ionized magnesium in undiluted serum, plasma or blood: International Federation of Clinical Chemistry and Laboratory Medicine (IFCC): IFCC Scientific Division, Committee on Point of Care Testing. Clin Chem Lab Med 2005; 43 (5): 564-569.

132. Dimeski G, Badrick T, John AS. Ion Selective Electrodes (ISEs) and interferences - a review. Clin Chim Acta 2010; 411 (5-6): 309-317.

133. Laurant P, Touyz RM. Physiological and pathophysiological role of magnesium in the cardiovascular system. J Hypertens 2000; 18 (9): $1177-1191$

134. Teragawa H, Matsuura H, Chayama K, Oshima T. Mechanisms responsible for vasodilation upon magnesium infusion in vivo: clinical evidence. Magnes Res 2002; 15 (3-4): 241-246.

135. Syllm-Rapoport I, Strassburger I, Grüneberg D, Zirbel C. Electrocardiographic studies in dogs with experimental magnesium deficiency. J Pediatr 1962; 60 (5): 801-804.

136. Ono $I$. The effect of varying dietary magnesium on the electrocardiogram and blood electrolytes of dogs. Jpn Circ J 1962; 26: 677-685.

137. Maksinovic R, Ketin S, Biocanin R. Interference of Bilirubin in the Determination of Magnesium with Methyl Thymol Blue. Mater Sociomed 2015; 27 (3): 192-194.

138. Elin RJ, Hristova EN, Cecco SA, Niemela JE, Rehak NN. Comparison of precision and effect of $\mathrm{pH}$ and calcium on the AVL and NOVA magnesium ion-selective electrodes. Scand J Clin Lab Invest Suppl 1996; 224: 203-210.

139. Ryan MF, Barbour H. Magnesium measurement in routine clinical practice. Ann Clin Biochem 1998; 35 (Pt 4): 449-459. 